\title{
Softening Behavior of Cold-Sprayed Aluminum-Based Coatings AA1200 and AA7075 During Annealing
}

\author{
K. Bobzin ${ }^{1} \cdot$ W. Wietheger ${ }^{1} \cdot$ J. Hebing $^{1} \cdot$ L. Gerdt $^{1}$ (D)
}

Submitted: 22 July 2020/in revised form: 30 September 2020/Accepted: 22 October 2020/Published online: 12 November 2020

(C) The Author(s) 2020

\begin{abstract}
For lightweight constructions, joining dissimilar metals is often indispensable to achieve exceptional properties. A common challenge is the bonding of steel and aluminum parts. The use of cold-sprayed coatings as a bonding agent is an innovative approach for high pressure die casting (HPDC) aluminum-steel hybrid components in order to achieve a metallurgical bonding, although it comes with high requirements in terms of coating adhesive and cohesive strength. Therefore, the main aim of this study is the optimization of a post-processing treatment of coldsprayed coatings in order to improve the cohesive strength to help the introduced coatings withstand the mechanical and thermal stresses during HPDC. The effect of the heat treatment on the mechanical properties of the cold-sprayed A199.0 and AA7075 coatings was investigated. Freestanding coatings were heat-treated at a temperature of $T=400{ }^{\circ} \mathrm{C}$ for different dwell times in order to analyze the recrystallization kinetics through hardness measurements. Two different heat treatment states along with an assprayed condition were chosen to investigate the evolution of the mechanical properties of the coatings by means of 3-point bending tests. Besides the softening of the coatings during the heat treatment, sintering effects at splat boundaries and their impact on fracture mechanisms were investigated using electron microscopy.
\end{abstract}

Keywords 3-point bending test · aluminum coatings . annealing $\cdot$ cold gas spraying $\cdot$ fracture mechanisms

\footnotetext{
L. Gerdt

gerdt@iot.rwth-aachen.de

1 Surface Engineering Institute, RWTH Aachen University, Kackertstraße 15, 52072 Aachen, Germany
}

\section{Introduction}

The application of coatings via cold gas spraying (CGS) for the high pressure die casting (HPDC) of aluminum-steel hybrid compounds has been analyzed in previous studies. Furthermore, the use of cold spraying technology for fluxfree brazing of aluminum alloys has been already investigated by Zhao et al. (Ref 1-3). It was shown that the deposition of AA7075 (AlZn5.5MgCu) and AA4145 (AlSi10Cu4) coatings on steel inserts can provide a better wetting by the aluminum melt during HPDC and, therefore, facilitate a solid metallurgical bonding between the aluminum and the steel parts (Ref 4-6). However, these coatings were prone to intersplat cracking either during casting due to the high kinetic energy of the aluminum melt, or afterward when loaded in shear tension. In order to improve the failure behavior of CGS coatings during HPDC, an increased bond strength between the splats is required. Heat treatment (HT) appears to be a promising solution to improve the ductility and to minimize the amount of intersplat cracking of the CGS coatings (Ref 79).

Rokni et al. (Ref 9) investigated the microstructure evolution of AA7075 deposits during different heat treatments. It was demonstrated that microstructure and resulting material properties such as ductility and tensile strength of the CGS coatings can be adjusted using heat treatment. The process gas used for cold gas spraying in the study was helium. However, in industrial applications, nitrogen is usually the first choice due to lower costs. Gaertner et al. (Ref 8) have showed that the process gas selection has a great impact on the cohesive bond strength and, therefore, mechanical properties of the cold-sprayed coatings. 
The microstructure of CGS coatings is characterized by a high degree of work hardening and a correspondingly high dislocation density. In addition, the splat boundaries, which are usually covered with oxide residues, are an important feature of the microstructure. These two factors usually lead to an increased brittleness of the coating compared to bulk materials. The recovery and recrystallization during the heat treatment can eliminate work hardening, as in the case of a cold-rolled material. Furthermore, diffusion mechanisms can be activated to promote the consolidation of individual particles, thus minimizing the negative effect of splat boundaries.

The main objective of this study was a comparative analysis of the mechanical properties of pure aluminum, and AA7075 coatings that were cold-sprayed using nitrogen as process gas, as well as their response to heat treatment. The relation between the mechanical properties within the splats and the bond strength on the splat boundaries was investigated depending on the heat treatment condition. Furthermore, the possible influence of second phase precipitations was of particular interest.

\section{Experimental Procedure}

The experimental procedure consisted of a cold gas spraying process, a microstructure analysis and mechanical investigations by means of 3-point bending tests. The experimental setup is described below.

\section{Coating Deposition by Cold Gas Spraying}

The pure aluminum coatings AA1200 (A199.0) and AA7075 (AlZn5.5MgCu) were produced using the Kinetics 8000 cold spray system by Oerlikon Metco (Pfäffikon, Switzerland) with nitrogen as process and carrier gas. The process parameters for the cold gas spraying are given in Table 1. The A199.0 powder with a size distribution of $-90+45 \mu \mathrm{m}$ and the AA7075 powder with a size distribution of $-63+20 \mu \mathrm{m}$ were delivered by GTV Verschleißschutz GmbH (Luckenbach, Germany) and TLS

Table 1 Cold gas spraying parameters for the deposition of A199.0 and AA7075

\begin{tabular}{llc}
\hline Parameters/powder & A199.0 & AA7075 \\
\hline Gas temperature, $T_{\mathrm{G}}\left({ }^{\circ} \mathrm{C}\right)$ & 380 & 400 \\
Process gas pressure, $\mathrm{N}_{2}(\mathrm{MPa})$ & 2.8 & 2.8 \\
Carrier gas flow, $\mathrm{N}_{2}\left(\mathrm{~m}^{3} / \mathrm{h}\right)$ & 3.0 & 3.0 \\
Spray distance $(\mathrm{mm})$ & 25 & 25 \\
Transverse velocity $(\mathrm{mm} / \mathrm{s})$ & 200 & 200 \\
\hline
\end{tabular}

Technik GmbH (Bitterfeld, Germany), respectively. The mild steel DC04 (1.0338) was used as substrate material for the coating deposition.

After the cold gas spraying process, the coatings were prepared by machining and subsequently ground, by analogy with the technique described in Ref 6. It is known that the upper layers of a CGS coating usually have a slightly higher porosity. This feature is based on the so-called tamping effect which describes a densification of the coating layers adjacent to the substrate due to an accumulative deformation resulting from the particle impact (Ref 10). Therefore, all coatings were ground using SiC paper with the grit number $\mathrm{P} 400$ from an initial thickness of approximately $d=1.4 \mathrm{~mm}$ to a thickness of $h=1.1 \mathrm{~mm}$ in order to minimize the possible influence of microstructural inhomogeneity and to avoid the surface roughness affecting the mechanical properties.

\section{Microstructure Characterization and Mechanical Testing}

In order to characterize the coatings, the cold-sprayed samples were metallographically prepared and examined in terms of their microstructure. In order to investigate the microstructure evolution of the coatings during the heat treatment, the samples were chemically etched with a DixKeller solution (Ref 11). The metallographic analysis was performed by means of the scanning electron microscope (SEM) Zeiss Leo 1530 (Jena, Germany) with the energy dispersive $\mathrm{x}$-ray spectroscopy (EDS) device Bruker Quantax 200 (Oak Park, USA) as well as the confocal laser scanning microscope (CLSM) VKX 210 by Keyence (Osaka, Japan). The electron backscatter diffraction (EBSD) analysis was performed at Access e. V. using a Gemini Leo 1550 scanning electron microscope by Carl Zeiss AG (Jena, Germany). A microhardness tester Buehler Micromet 1 by ITW Test \& Measurement GmbH (Esslingen am Neckar, Germany) was used for the examination of the coating hardness HV0.025 with a load of $m=25 \mathrm{~g}$. A total of 6 measurements per sample were conducted. The 3point bending tests were conducted at Access e. V. using the SEMTester 2000 by MIT Instruments Inc. (Albany, USA) with a deflection rate of $\dot{\delta}=0.2 \mathrm{~mm} / \mathrm{min}$. The samples with the dimensions $l=40 \mathrm{~mm}, b=4 \mathrm{~mm}$ and $h=1.1 \mathrm{~mm}$ were prepared as described in Sect. 2.1. The measurements were carried out at 3 samples for each coatings condition. The longitudinal axis of the samples was perpendicular to the spray direction. 


\section{Results}

\section{Recovery and Recrystallization}

The development of the coating hardness during the heat treatment of strain-hardened materials can be used as an indication of recrystallization or recovery. For the investigations, a typical temperature of $T=400{ }^{\circ} \mathrm{C}$ was selected for soft annealing the AA7075 alloy. Due to alloying elements such as $\mathrm{Zn}$ and $\mathrm{Mg}$, the precipitation of a second phase in the coating is expected in addition to the recovery and recrystallization. The precipitation sequence of the AA7075 alloy has already been investigated in detail and includes the following steps: $\alpha$ solid solution Cluster Guinier-Preston GP-zones $\eta^{\prime} \eta\left(\mathrm{MgZn}_{2}\right)$ or $\mathrm{T}\left((\mathrm{Al}, \mathrm{Zn})_{49-}\right.$ $\left.\mathrm{Mg}_{32}\right)$ (Ref 12-14).

The coatings were heat-treated for different durations ranging between $t_{\mathrm{HT}}=2 \mathrm{~min}$ to $t_{\mathrm{HT}}=3 \mathrm{~h}$. Figure 1 shows the results of the hardness measurements of the A199.0 and AA7075 cold-sprayed coatings after different heat treatment times. The initial hardness of the pure $\mathrm{Al}$ coating after the deposition was $H=46.6 \pm 1.4 \mathrm{HV} 0.025$. A reduction in Vickers hardness of approximately $20 \%$ corresponds to the condition after the heat treatment for $t_{\mathrm{HT}}=5 \mathrm{~min}$. After a heat treatment duration of $t_{\mathrm{HT}}=10 \mathrm{~min}$, the hardness reached a plateau, after which the hardness values did not change significantly with an increasing holding time up to $t_{\mathrm{HT}}=1 \mathrm{~h}$. Upon further increase of the holding time up to $t_{\mathrm{HT}}=3 \mathrm{~h}$, the Vickers hardness of the Al99.0 coating was further reduced to $H=24.1 \pm 1.4$ HV0.025.

For the AA7075 coating, the hardness development was more dynamic with a hardness decrease of approximately $38 \%$ after $t_{\mathrm{HT}}=5 \mathrm{~min}$. After an increased holding time up to $t_{\mathrm{HT}}=3 \mathrm{~h}$, the hardness reached the minimum of $H=82.4 \pm 3.4$ HV0.025. With $H=144.7 \pm 3.5$ HV0.025, the hardness of the AA7075 coating in as-sprayed condition corresponds approximately to the deformation state of the cold-rolled material after a thickness reduction of $\varepsilon=75 \%$
$(H=142$ HV0.3) (Ref 15). De Sousa et al. observed a completely recrystallized microstructure after a heat treatment at $T=400{ }^{\circ} \mathrm{C}$ already after $t_{\mathrm{HT}}=15 \min (\operatorname{Ref} 15)$.

Based on the hardness evolutions of both coatings during annealing, two heat treatment, one at $t_{\mathrm{HT}}=20 \mathrm{~min}$ and the other at $t_{\mathrm{HT}}=3 \mathrm{~h}$, were selected for a further characterization of the microstructure by CLSM and SEM analyses and the mechanical properties by 3-point bending test. One of the objectives was to clarify whether a short heat treatment of $t_{\mathrm{HT}}=20 \mathrm{~min}$ is sufficient for a significant increase of the ductility of the coatings.

\section{Microstructure Evolution}

In the as-sprayed condition, the A199.0 coating has a fine crystalline structure with an average grain size of approximately $5 \mu \mathrm{m}$, Fig. 2(a). In addition to areas with a pronounced deformation structure with characteristically elongated grains, areas with no or slight deformation can be found. This indicates an inhomogeneous deformation of individual particles during cold gas spraying. After heattreating for $t_{\mathrm{HT}}=20 \mathrm{~min}$, splat boundaries are still clearly visible in the cross-section. The internal microstructure of the splats, however, becomes less visible. A possible reason for this is the recovery of the microstructure during heat treatment, which leads, among other things, to a reduced dislocation density. The dislocations are accumulated in a deformed structure, especially at the grain boundaries. As the etching solutions act especially in areas with a high number of defects such as voids or dislocations, representation of the microstructure inside the splats after heat treatment becomes more difficult. Heat-treating the coating for a longer holding time of $t_{\mathrm{HT}}=3 \mathrm{~h}$ does not show a significant impact on the microstructure compared to $t_{\mathrm{HT}}=20 \mathrm{~min}$.

The AA7075 coating in the as-sprayed state reveals a fine-grained microstructure with a pronounced segregation at the grain boundaries, Fig. 3(a). This is clearly visible in
Fig. 1 Coating hardness after different heat treatment durations $T=400{ }^{\circ} \mathrm{C}$ $(t=0$ min corresponds to assprayed condition) for (a) A199.0 coating and (b) AA7075 coating
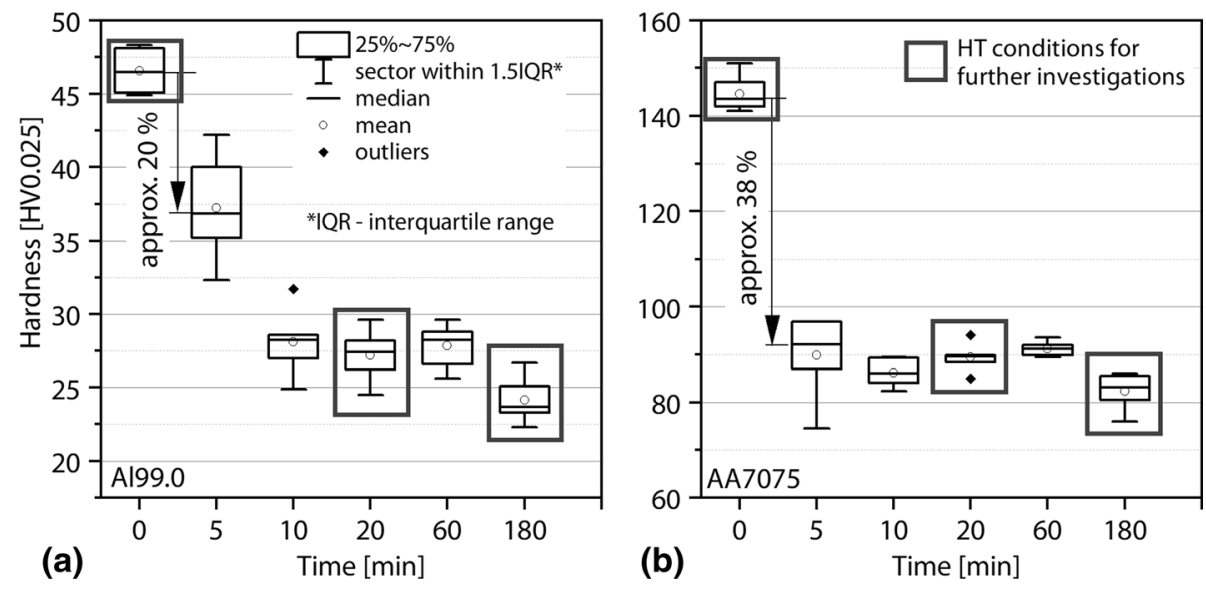

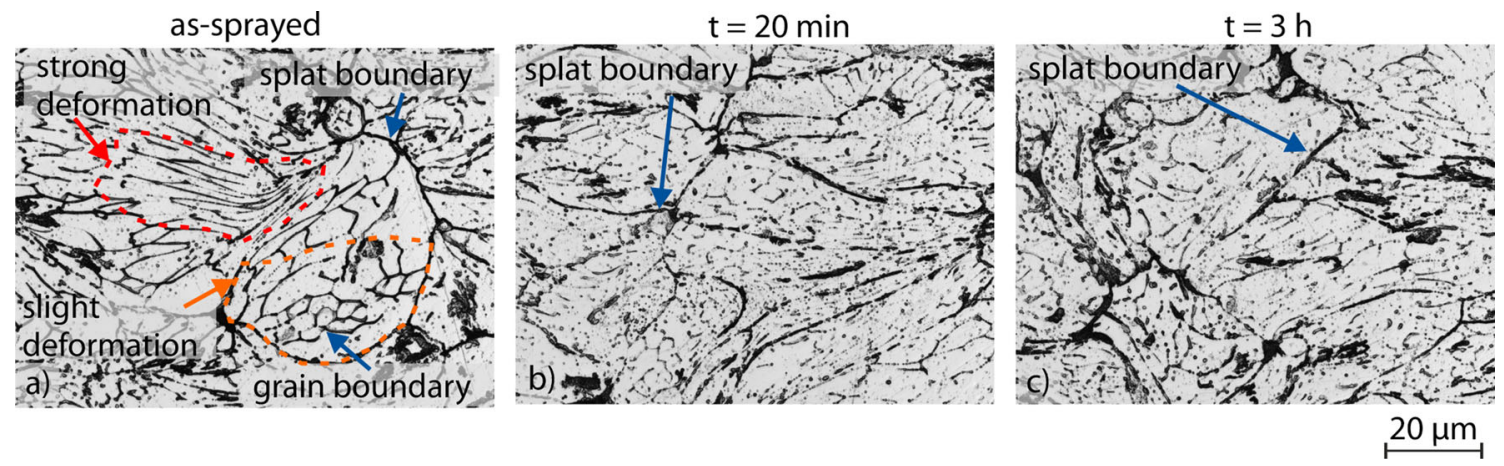

Fig. 2 CLSM micrographs of A199.0 coating (a) in as-sprayed condition, (b) after heat treatment for $t_{\mathrm{HT}}=20$ min, (c) after heat treatment for $t_{\mathrm{HT}}=3 \mathrm{~h}\left(T=400{ }^{\circ} \mathrm{C}\right)$
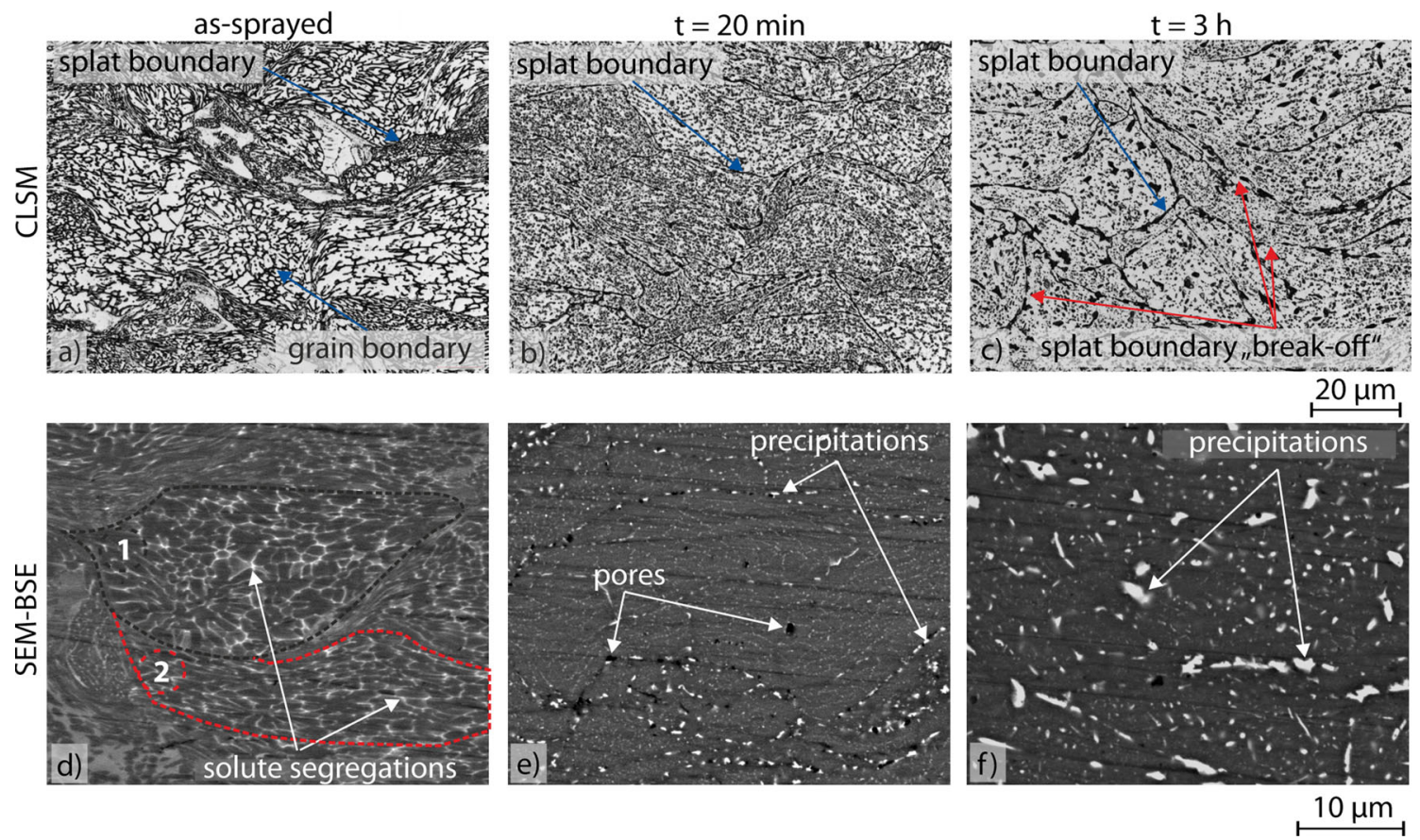

Fig. 3 CLSM and SEM-BSE micrographs of AA7075 coating (a) and (d) in as-sprayed condition (b) and (e) after heat treatment for $t_{\mathrm{HT}}=20 \min (\mathrm{c})$ and (f) after heat treatment for $t_{\mathrm{HT}}=3 \mathrm{~h}\left(T=400{ }^{\circ} \mathrm{C}\right)$

the SEM-BSE images, as backscattered electrons (BSE) provide a good material contrast. The mechanisms that lead to the segregation of the alloying elements at the grain boundaries in $\mathrm{AlMgZnCu}$ alloys have already been described in detail in the literature (Ref 14, 16). In Fig. 3(d), it can also be seen that some powder particles, such as particle 1 , were only slightly deformed during the coating deposition. At the same time, particle 2 was deformed much more strongly, which is indicated by elongated grains in the microstructure. The heat treatment with a holding time of $t_{\mathrm{HT}}=20 \mathrm{~min}$ resulted in coagulation of the precipitates of the second phase within the splats and growth of the precipitates at the splat boundaries, Fig. 3(e). In addition, there are occasionally pores at the splat boundaries. Similar to the pure Al99.0 coating, the splat boundaries remain visible even after a prolonged heat treatment for $t_{\mathrm{HT}}=3 \mathrm{~h}$. However, they are locally interrupted, especially in the vicinity of the coarse particles of the second phase, Fig. 3(c). An increased holding time of the heat treatment to $t_{\mathrm{HT}}=3 \mathrm{~h}$ further resulted in a coarsening of the precipitates, Fig. 3(f). The original grain boundaries within the splats are no longer visible after a longer heat treatment time.

In order to be able to trace the microstructure development within individual splats, SEM-EBSD analyses of the AA7075 coatings were performed in the initial state and after heat treatment for $t_{\mathrm{HT}}=3 \mathrm{~h}$. The fine crystalline microstructure of the coating in the as-sprayed state can be 


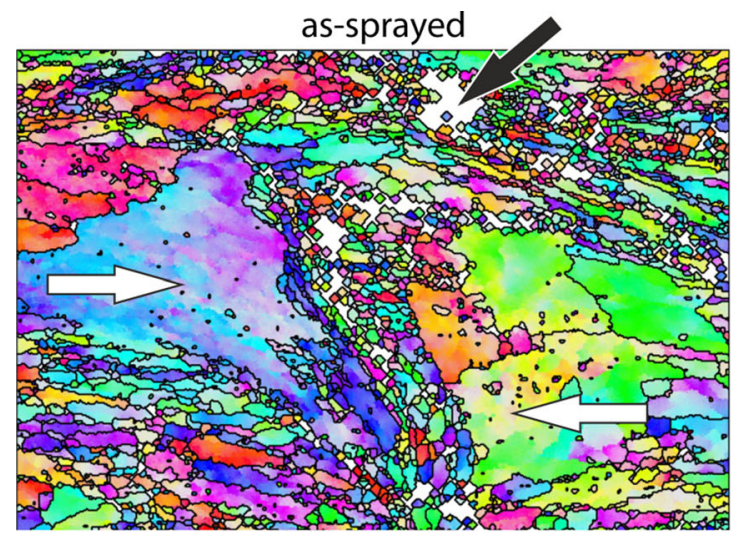

(a) [111]

[001]
[111] [011]

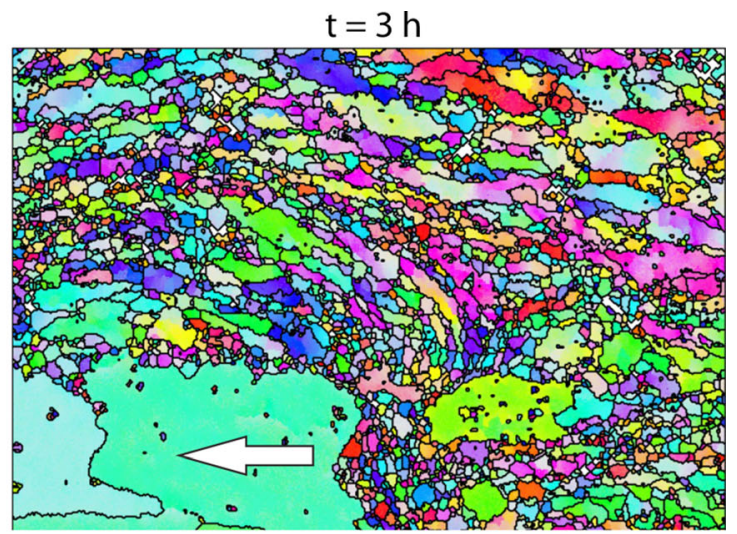

(b)
$10 \mu \mathrm{m}$

Fig. 4 EBSD mappings of AA7075 coatings (a) in as-sprayed condition and (b) after heat treatment for $t_{\mathrm{HT}}=3 \mathrm{~h}\left(T=400{ }^{\circ} \mathrm{C}\right)$

seen particularly well on the SEM-EBSD image in Fig. 4(a). The two white arrows mark two large grains with minor disorientation inside the grains, indicating a slight deformation of these particles. Identification of the crystallographic orientation in the as-sprayed state was difficult, probably due to a high degree of deformation, see white non-indexed areas in Fig. 4(a) (marked with a black arrow). It is known that an increased number of defects such as dislocations in the deformed microstructure can make the evaluation of EBSD patterns significantly more difficult (Ref 17). The quality of the EBSD mappings after heat treatment has improved significantly compared to the condition after coating application. This can be attributed to the recovery and recrystallization processes, which result in an annihilation of the vacancies and dislocations. EBSD analysis directly after heat treatment does not reveal noticeable grain growth, Fig. 4(b). A possible reason for this may be the prevention of grain boundary mobility by the fine precipitation network at the grain boundaries.

On the one hand, the coarse particles can promote nucleation and grain growth. The fine grain boundary precipitates, on the other hand, inhibit dislocation movement and grain boundary migration (Ref 18). During the heat treatment of the coatings, a fine network of grain boundary precipitates is present at least up to a heat treatment time of $t_{\mathrm{HT}} \leq 20 \mathrm{~min}$, see Fig. 3. It is assumed to prevent movement in the grain boundaries and, therefore, grain growth of the recrystallized microstructure. Coarsening the precipitates at a later point in time does not promote a nucleation of new grains, as the driving force for recrystallization is no longer present at this point, see Fig. 1(b). It can therefore be assumed that the main mechanism leading to the softening of the coating during heat treatment is based on recovery. Disorientation within individual splats also decreases significantly due to recrystallization, which also speaks for the removal of the deformation structure.

\section{Characterization of the Mechanical Properties}

The influence of the heat treatment on the mechanical behavior of the coatings was investigated using a 3-point bending test. For this purpose the coating was detached from the substrate as shown in Fig. 5(a). Figure 5(b) schematically shows the experimental arrangement of the 3-point bending test and the correlation of the sample geometry with the relevant cold gas spraying direction.

All samples were mechanically processed by cutting and subsequently ground to the dimension $l \times b \times h=40 \times$ $4 \times 1.1 \mathrm{~mm}$. This specimen geometry was selected in accordance with the American standard for bending tests on sheet and strip for springs ASTM E 855 - 08 (Ref 19).The bending stress-deflection diagrams in Fig. 6 were then calculated from the force $F$. The bending stress $\sigma_{\mathrm{B}}$ is calculated as:

$\sigma_{\mathrm{B}}=\frac{3 \cdot F \cdot L}{2 \cdot b \cdot h^{2}}$

In as-sprayed condition, both coatings show a brittle behavior under bending loads. In the case of the pure A199.0 coating, even the short heat treatment with a holding time of $t_{\mathrm{HT}}=20 \mathrm{~min}$ led to a significant increase in ductility, which resulted in an increased fracture bending strain of the specimens. The flexural strength was reduced from $\sigma_{\mathrm{B}} \approx 125 \mathrm{MPa}$ to $\sigma_{\mathrm{B}} \approx 100 \mathrm{MPa}$. The heat treatment with an increased holding time of $t_{\mathrm{HT}}=3 \mathrm{~h}$ only 


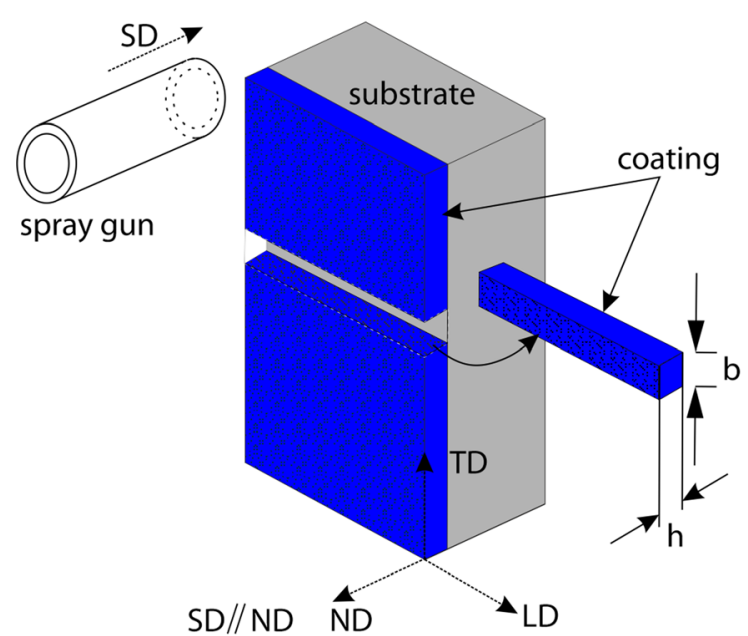

(a)

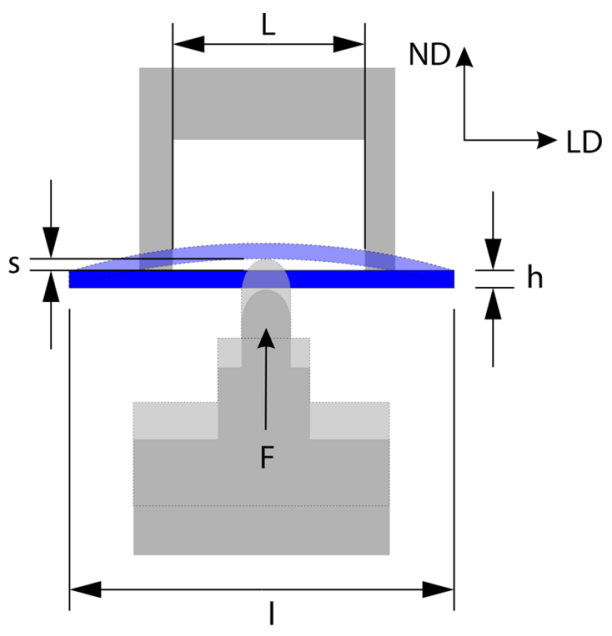

(b)

Fig. 5 (a) Schematic representation of the sample preparation and (b) schematic structure of the 3-point bending test (ND normal direction, $S D$ spray direction, $L D$ longitudinal direction, $T D$ transverse direction)

Fig. 6 Bending stressdeflection diagrams in the assprayed state and after heat treatment at $T=400{ }^{\circ} \mathrm{C}$ for (a) A199.0 coating and (b) AA7075 coating
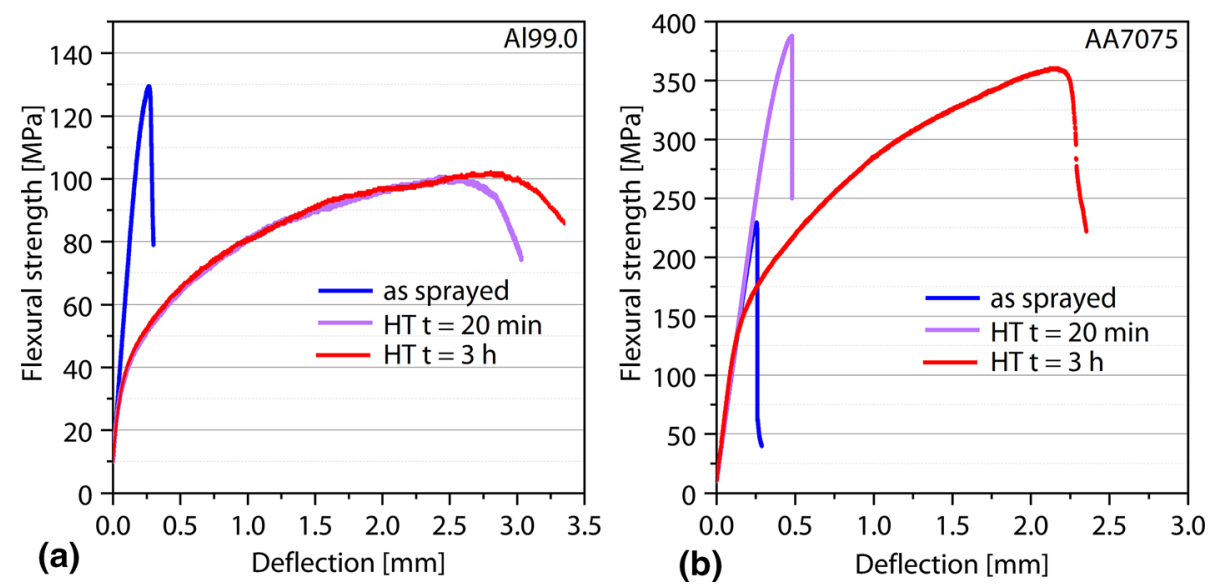

slightly increased the deflection and bending strength of the coating.

In case of the AA7075 coating, the effect of a short heat treatment with a holding time of $t_{\mathrm{HT}}=20$ min was characterized by an increase in flexural strength from $\sigma_{\mathrm{B}-}$ $\approx 211 \mathrm{MPa}$ to approximately $\sigma_{\mathrm{B}} \approx 406 \mathrm{MPa}$, Fig. 6(b). The bending strain at the break increased only marginally, which led to noticeable plastic deformation of the coating. Only the longer heat treatment with $t_{\mathrm{HT}}=3 \mathrm{~h}$ led to a significant increase in ductility with a slight decrease in flexural strength compared to the condition after $t_{\mathrm{HT}}=20 \mathrm{~min}$.

Figure 7 shows examples of the fracture surfaces of the specimens after the 3-point bending test. The SEM images confirm the assumption that both coatings show no signs of plastic deformation in the as-sprayed state. In case of the A199.0 coating in the as-sprayed state, isolated pores and splats are clearly visible. The fracture pattern indicates a preferred crack propagation path along splat boundaries.
Already after heat-treating for a holding time of $t_{\mathrm{HT}-}$ $=20 \mathrm{~min}$, some areas of plastic deformation became visible. These are circled with blue lines in Fig. 7. The honeycomb-structured area characteristic for plastic deformation increased further with an increasing heat treatment time from $t_{\mathrm{HT}}=20 \mathrm{~min}$ to $t_{\mathrm{HT}}=3 \mathrm{~h}$.

The AA7075 coating showed a similar fracture pattern in as-sprayed condition as the pure Al99.0 coating. After a short heat treatment with a holding time of $t_{\mathrm{HT}}=20 \mathrm{~min}$, merely small, spatially separated areas with plastic deformation could be detected, Fig. 7(e). Only after a longer heat treatment time of $t_{\mathrm{HT}}=3 \mathrm{~h}$, an increase of the areas with ductile dimples could be detected, which reflects an increased ductility of the coating, Fig. 7(f).

Furthermore, second phase precipitates could be detected in the fracture surface. In order to investigate a possible effect of the precipitates on the mechanical properties of the CGS coatings, further cross-sectional images were 

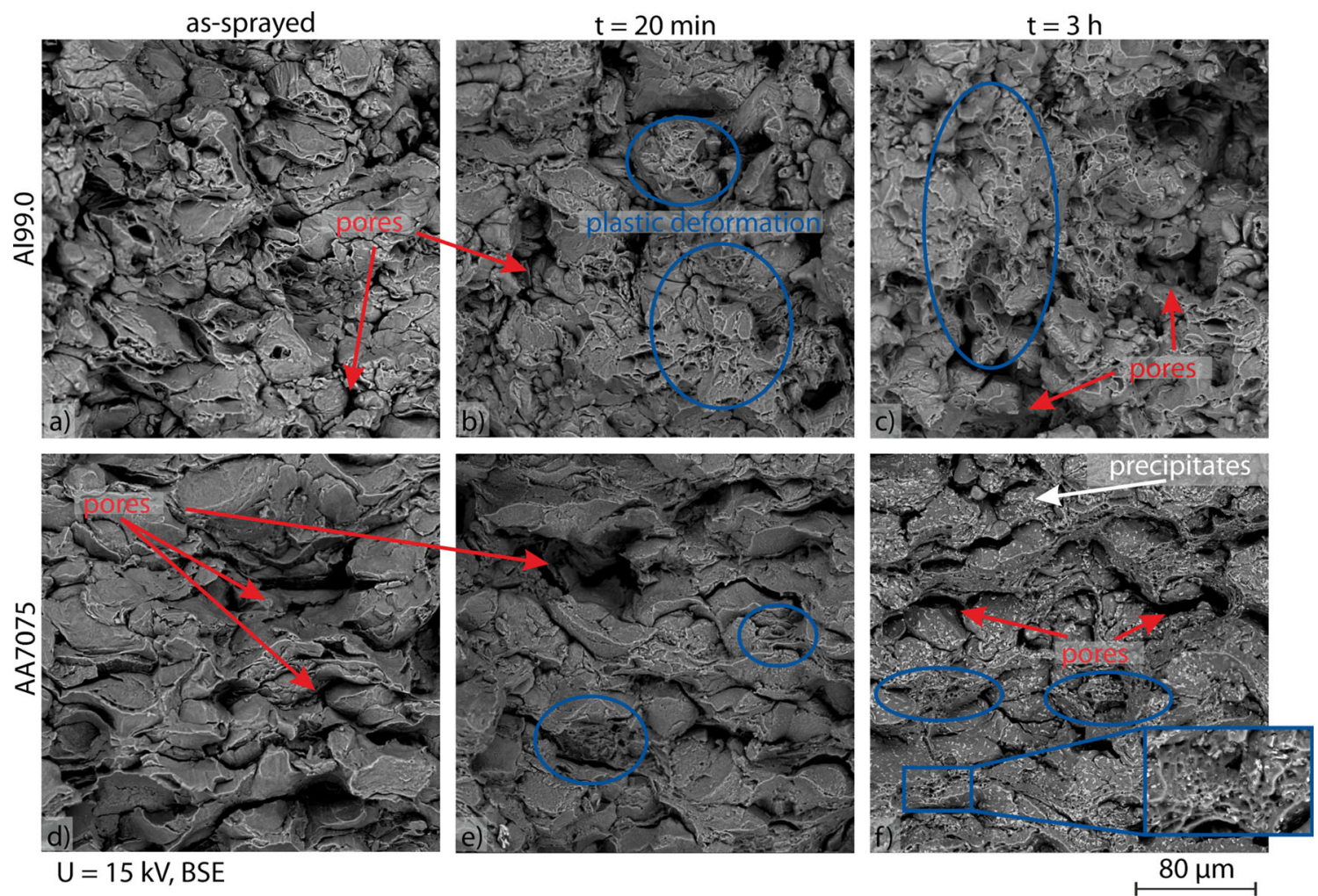

Fig. 7 Fracture surface of the samples after the 3-point bending test of A199.0 and AA7075 coatings in as-sprayed condition, after heat treatment with $t_{\mathrm{HT}}=20$ min as well as after heat treatment with $t_{\mathrm{HT}}=3 \mathrm{~h}\left(T=400{ }^{\circ} \mathrm{C}\right)$

analyzed by means of CLSM and SEM-BSE in addition to the fracture surfaces, Fig. 8 .

In case of the AA7075 coating in as-sprayed condition, a clear preference of crack propagation along splat boundaries is visible, Fig. 8(b) and (e). This characteristic crack propagation is maintained even after heat treatment for $t_{\mathrm{HT}}=20 \mathrm{~min}$. It is evident from the contours of the individual splats that they were detached from the adjacent particles during the 3-point bending test, Fig. 8(c). Initially, there is no correlation between the distribution of the precipitates in the microstructure and the crack paths, Fig. 8(e) and (f). Even after increasing the heat treatment time to $t_{\mathrm{HT}}=3 \mathrm{~h}$, crack propagation along the boundaries of the splats is visible to some extent, Fig. 8(d). Nevertheless, a transition from a pure brittle fracture to a mixed fracture with increasing heat treatment time is clearly visible. Furthermore, coarse precipitations can be observed at the crack edges, Fig. 8(g). As was already determined in the analysis of the microstructure development, such precipitates are preferably found at splat boundaries. This observation supports the assumption that crack propagation mainly progresses through splat boundaries.

The analysis of the crack propagation in the A199.0 coating after the 3-point bending test was carried out using CLSM. Cross-sectional images are shown in Fig. 9. In assprayed condition, a preferred crack propagation along splat boundaries is clearly visible. Figure 9(d) shows that individual splats were torn away from adjacent ones without plastic deformation. The subsequent heat treatment causes softening, cf. Figure 1 and 6, which results in a better formability. Already after a short heat treatment time of $t_{\mathrm{HT}}=20 \mathrm{~min}$, areas with a strong plastic deformation after bending test can be found near the crack, Fig. 9(e). It can be seen that the cracks partly go through the interior of some splats. The total area featuring the transgranular crack propagation increases with an increasing holding time of the heat treatment, Fig. 9(c) and (f). Thus, the pure A199.0 coating shows a faster response to the heat treatment compared to the AA7075 coating exhibiting a clear transition from pure brittle fracture to partially ductile fracture already after heat treatment with $t_{\mathrm{HT}}=20 \mathrm{~min}$.

\section{Correlation Between Microstructure Development and Fracture Behavior of CGS Coatings}

This chapter will introduce a model to describe the fracture behavior of CGS coatings and the correlation between the deformation and the heat treatment state of these coatings. Furthermore, the difference between the two coatings with respect to the transition from brittle cohesive failure to mixed failure will be explained. The strength of the coating is considered as a function of the cohesive strength at the 
a) sample after 3-point bending test
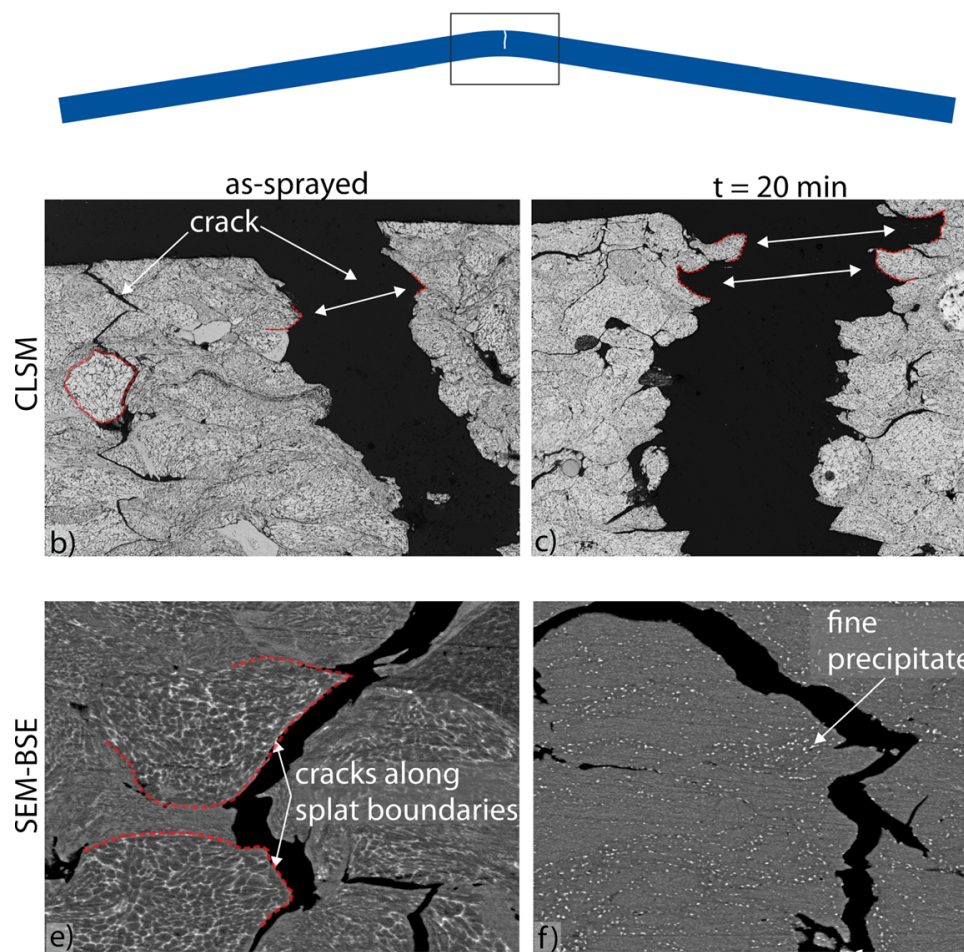

analyzed area

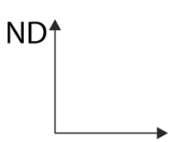

LD

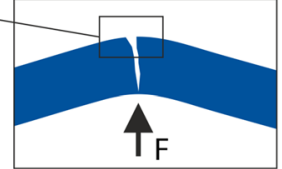

$t=3 h$
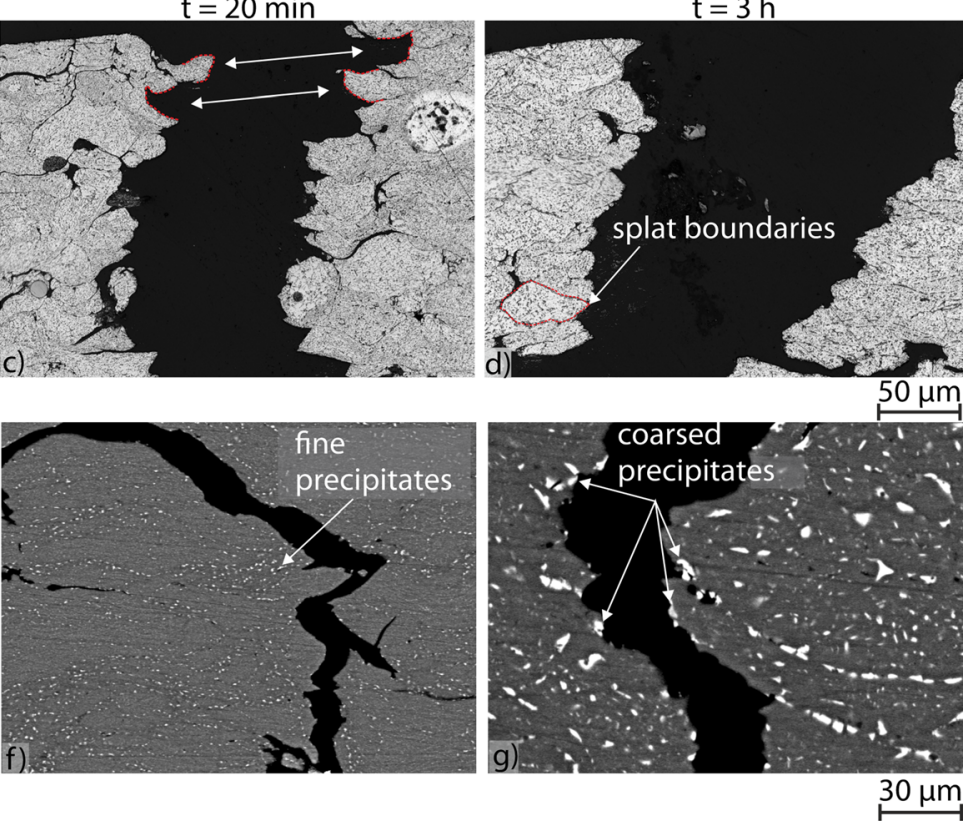

Fig. 8 (a) Schematic diagram of the analyzed areas on the samples of AA7075 coating after 3-point bending test and CLSM micrographs of the cracked samples (b) in as-sprayed condition, (c) after heat treatment for $t_{\mathrm{HT}}=20 \mathrm{~min}$, (d) after heat treatment for $t=3 \mathrm{~h}$ as well as SEM-BSE micrographs of the cracked samples (e) in as-sprayed condition, (f) after heat treatment for $t_{\mathrm{HT}}=20 \mathrm{~min}$, (g) after heat treatment for $t=3 \mathrm{~h}$
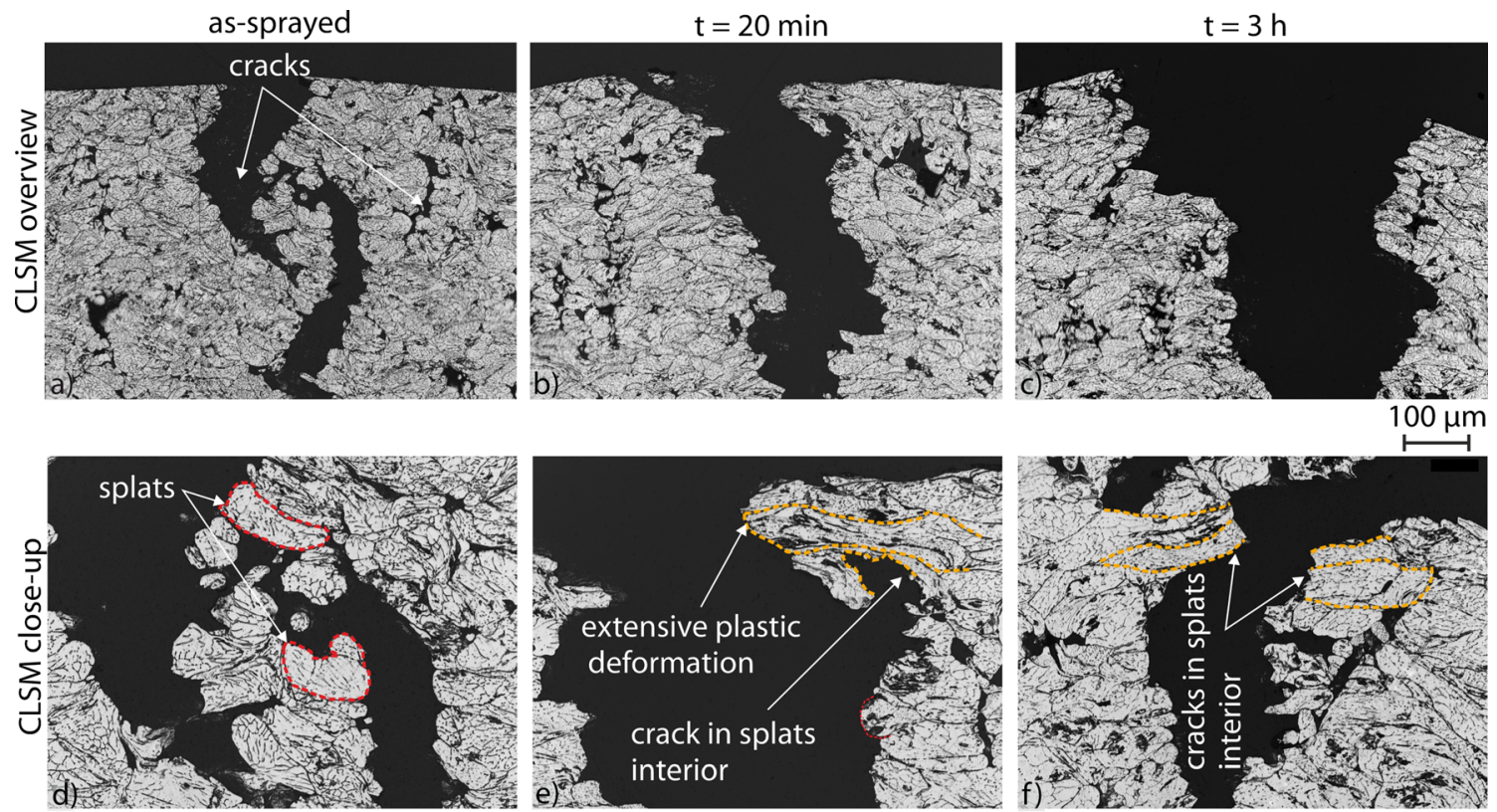

$30 \mu \mathrm{m}$

Fig. 9 CLSM micrographs of cracked samples of the A199.0 coating after the 3-point bending test in as-sprayed condition, after heat treatment for $t_{\mathrm{HT}}=20 \mathrm{~min}$ and for $t_{\mathrm{HT}}=3 \mathrm{~h}\left(T=400{ }^{\circ} \mathrm{C}\right)$ 
splat boundaries $\sigma_{\mathrm{H}}$ (cohesive) and the material properties within the individual splats the tensile strength $R_{\mathrm{m}}$ (splat) or yield strength $R_{\mathrm{e}}$ (splat):

$\sigma_{\mathrm{B}}($ coating $)=f\left(R_{\mathrm{m}} / R_{\mathrm{e}}(\right.$ splat $), \sigma_{\mathrm{H}}($ cohesion $\left.)\right)$

The introduced parameters are dependent on the material, the particle size, the deformation state as well as the process parameters of cold gas spraying. The strength values can also vary locally within the coating. The reason for this is inhomogeneities in the microstructure of the coating. These result from the different degrees of deformation and consequently the different deformation states of individual particles. Heat treatment can cause a transformation of this state and consequently lead to a change in the mechanical properties. A sequence of microstructure development of the AA7075 coating during heat treatment is schematically shown in Fig. 10. It includes the formation and coagulation of the precipitates of the second phase and, further, their coarsening as well as recovery processes within splats interior. In the splat boundary regions continuous sintering process results in partial boundary "break offs" at the late stages of the heat treatment $t=3 \mathrm{~h}$.

The specific mechanical properties inside splats and the cohesive strength at splat boundaries differ for each heat treatment condition. First, the microstructure development and its influence on the mechanical properties within the splats are considered. For the pure Al99.0 coating, it is mainly the work hardening state of the material that is responsible for a high hardness after the CGS process. In case of the AA7075 coating, the effect of solid solution hardening or precipitation hardening is also important. In the as-sprayed condition, a segregation of the alloying elements at the grain boundaries could be demonstrated, cf. Figure 3(d). A formation of GP zones or the partially coherent $\eta$ phase can still be assumed when taking into account the heat input during coating application $\left(380{ }^{\circ} \mathrm{C}<T_{\mathrm{G}}<400{ }^{\circ} \mathrm{C}\right)$. Heat treatment commonly triggers a dislocation movement and leads to an annihilation of defects. Furthermore, in case of the AA7075 coating, a coarsening of second phase precipitates could be observed metallographically, cf. Fig. 3. Both mechanisms lead to a softening of the material and consequently to a decrease in hardness, Fig. 11(a).

In addition to the development of the mechanical properties within the splats during heat treatment, changes at the splat boundaries can be expected. These include a possible reduction of the total porosity or a coagulation of the pores at the splat boundaries as well as a consolidation of individual particles by diffusion processes, as has already been shown in other studies (Ref 7,20$)$. The quality of the interfacial contact of the metallic surfaces of adjacent splats is of decisive importance here. Since aluminum powder or aluminum alloys have an oxidized surface after the manufacturing process, they can reduce the quality of the bond between individual particles during cold gas spraying. Most of the existing models for describing the adhesion mechanisms in CGS require the surface oxide layer of the powder to be mechanically broken up upon particle impact. The reason for this is the strong plastic deformation of the spray particles and their dissipation of frictional heat (Ref 21-23).

The above-mentioned models are mainly based on simulation results. An experimental investigation of the influence of the surface oxide layer on adhesion mechanisms during cold gas spraying is difficult due to high particle velocities. The break-up of the aluminum oxide layer due to the strong mechanical deformation of powder particles has already been demonstrated, for example, in equal channel angular pressing (ECAP) (Ref 24). However, it should be noted that the broken oxide particles remain at the splat boundaries and cover a significant proportion of the interface. Therefore, the splat boundaries of a coating usually represent a weak point with regard to tensile or bending loads.

An investigation of the processes taking place at the splat boundaries during heat treatment was carried out by means of metallographic analyses. The CLSM images in
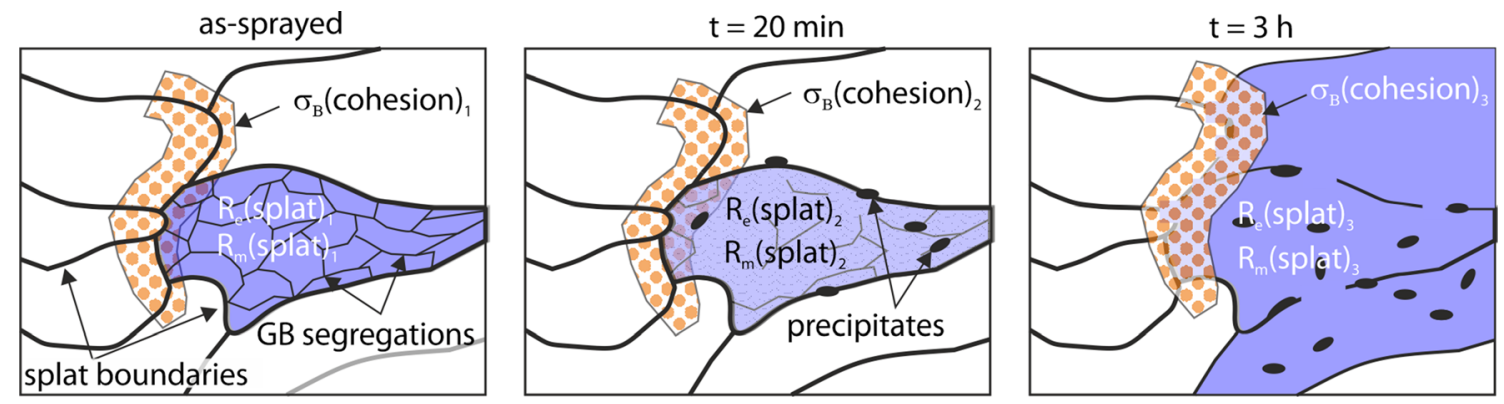

Fig. 10 Model of the microstructure development of the CGS coatings during heat treatment with corresponding changes of the mechanical properties of the coatings (dotted region representing splat boundaries responsible for cohesive strength of the coating, blue and pale blue regions representing splat interior with precipitates of the second phase responsible for material strength inside splats) 


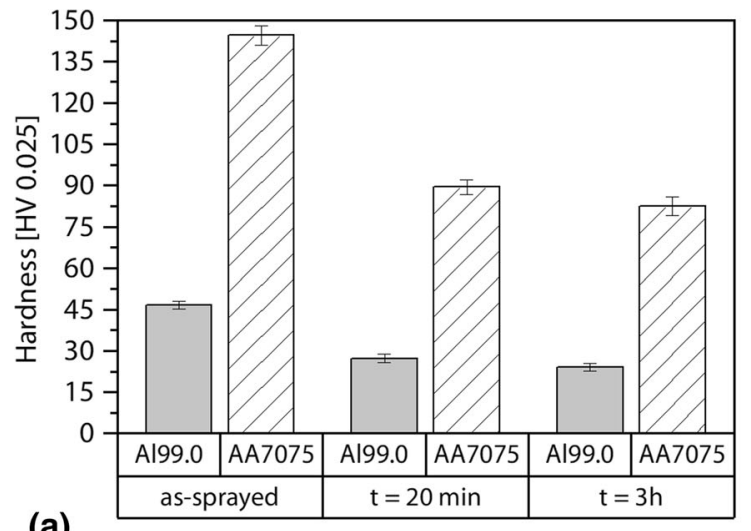

(a)

Fig. 11 Comparison of the (a) hardness and (b) bend strength of the coatings after different heat treatments at $T=400{ }^{\circ} \mathrm{C}$

(b)
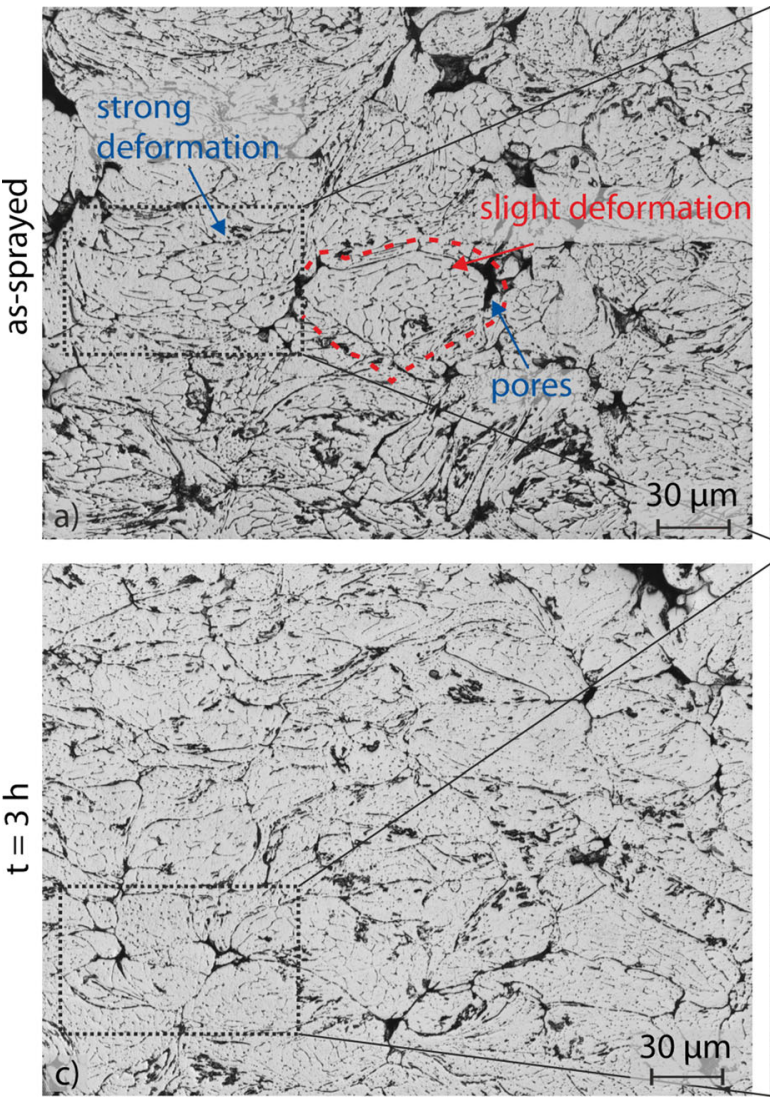
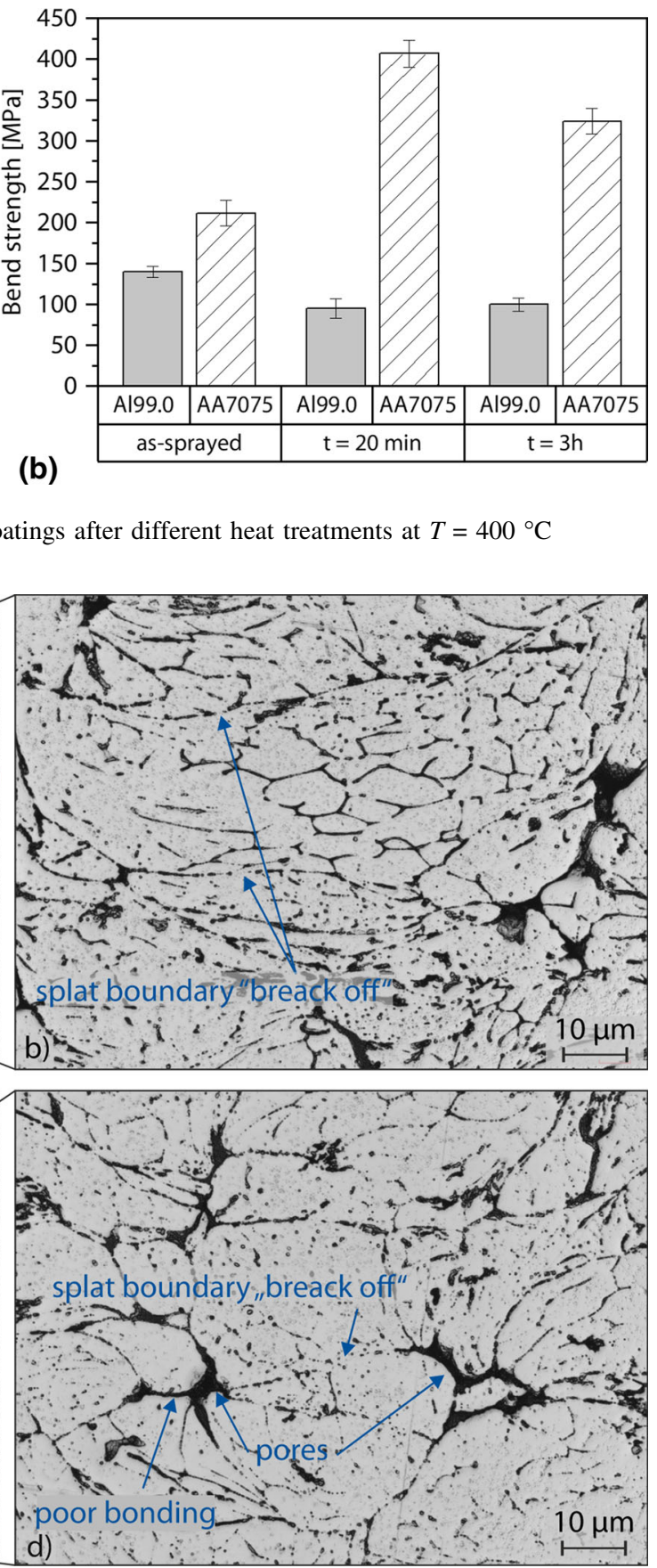

Fig. 12 CLSM micrographs of the Al99.0 coating in as-sprayed condition and after heat treatment at $T=400{ }^{\circ} \mathrm{C}$ for $t_{\mathrm{HT}}=3 \mathrm{~h}\left(T=400{ }^{\circ} \mathrm{C}\right)$

Fig. 12 display local inhomogeneities in the bond between the particles of the A199.0 coating in as-sprayed condition.

A possible reason for these inhomogeneities is the varying degrees of particle deformations due to the varying particle sizes and particle velocities during cold gas spraying. The microstructure of the coating suggests that the more strongly deformed splats sometimes have a material bond with their neighbors. Meanwhile, the interfaces between the less deformed particles can be identified better. Furthermore, large pores are predominantly found in the vicinity of such splats, Fig. 12(a) and (b). Neither a significant change in the morphology of the splat boundary nor an improvement in the bond between particles after the heat treatment could be metallographically proven, even after $t_{\mathrm{HT}}=3 \mathrm{~h}$. Nevertheless, for the A199.0 coating, a statement can be made about the relationship between the cohesive strength at the splat boundaries and the strength inside the splats. Thus, the fractographic and 
metallographic analyses of the cold gas-sprayed coating after the 3-point bending test indicate a purely cohesive failure of the coating along the splat boundaries without plastic deformation of the splats. Therefore, the bending strength of the coating in this case is determined by the cohesive strength $\sigma_{\mathrm{B}}=f\left(\sigma_{\mathrm{H}}(\right.$ cohesive $\left.)\right)$. This means that the coating fails before plastic deformation occurs inside the splats. The heat treatment of the coating leads to a significantly reduced hardness and consequently probably to a decrease in the yield strength $\operatorname{Re}(\text { splat })_{2}<\operatorname{Re}$ (splat) $)_{1}$ (considering Fig. 10). For the A199.0 coating, even a short heat treatment for $t_{\mathrm{HT}}=20 \mathrm{~min}$ results in a state with $\operatorname{Re}(\text { splat })_{2} \leq \sigma_{\mathrm{H}}$ (cohesive $)_{2}$.

This is also indicated by the fracture pattern after the heat treatment for $t_{\mathrm{HT}}=20 \mathrm{~min}$, which features approximately equal proportions of ductile and brittle fracture. The increase in ductility of the pure A199.0 coating can therefore be achieved even after a relatively short heat treatment time, as soon as the condition $\operatorname{Re}$ (splat) $\leq \sigma_{\mathrm{H}}$ (cohesive) is reached. With regard to the AA7075 coating, the changes at the splat boundaries after the heat treatment are metallographically clearly visible. In addition to the interruption of the interfaces, cf. Figure 13, a precipitation of a second phase at the splat boundaries could be detected. Similar to the A199.0 coating, an inhomogeneous quality of the bond between adjacent splats was observed here as well. Isolated pores are primarily found at points where several particles meet, or in areas of low deformation. The AA7075 coating exhibits purely cohesive failure in as-sprayed state. It can therefore be assumed that the initial adhesion between particles plays a decisive role for the overall strength of the coating $\sigma_{\mathrm{B}}=f\left(\sigma_{\mathrm{H}}\right.$ (cohesive $\left.)\right)$. In contrast to the pure $\mathrm{Al}$ coating, a short heat treatment for $\mathrm{t}_{\mathrm{HT}}=20$ min leads to an increased bending strength. However, the failure of the coating remains brittle for the most part, as shown by the fracture analysis, cf. Fig. 7. Nevertheless, isolated areas featuring crack propagation through gaps could be detected, cf. Fig. 7 and 8. A clear localization of such areas indicates inhomogeneous mechanical properties and a different relationship between $\sigma_{\mathrm{H}}$ (cohesive) and Re(splat) across the sample cross-section. The fracture pattern of the AA7075 coating and the bending stress curve indicate that the $\sigma_{\mathrm{H}}(\text { cohesive })_{2}<\operatorname{Re}(\text { splat })_{2}$ condition prevails after a heat treatment for $t_{\mathrm{HT}}=20 \mathrm{~min}$ despite a decrease in hardness, Fig. 11. The microstructure analysis shows that in this heat treatment state, the second phase precipitates are still finely and homogeneously distributed, which is
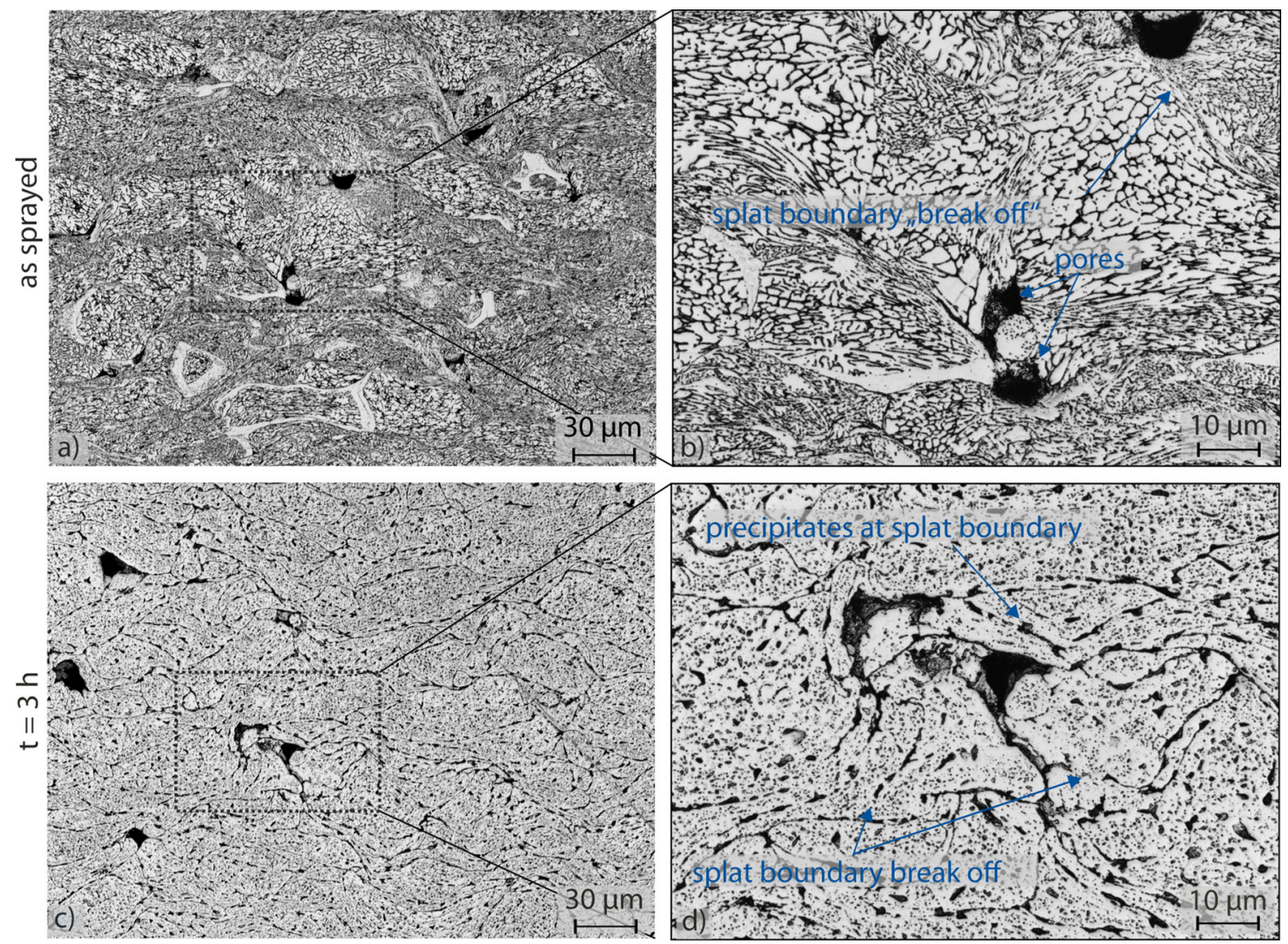

Fig. 13 CLSM cross-sectional images of the AA7075 coating in as-sprayed condition and after heat treatment at $T=400{ }^{\circ} \mathrm{C}$ for $t_{\mathrm{HT}}=3 \mathrm{~h}$ $\left(T=400{ }^{\circ} \mathrm{C}\right)$ 
likely to be the reason for the high strength inside the splats, Fig. 3(f).

Only after a longer heat treatment for $t_{\mathrm{HT}}=3 \mathrm{~h}$ is a significant increase in coating ductility achieved. Here, it is presumably the total fraction under the condition $\operatorname{Re}$ (splat) $)_{3}<\sigma_{\mathrm{H}}$ (cohesive) $)_{3}$ that increases in the coating. Thus, the stresses induced into the coating during the bending test can be locally reduced via plastic deformation. Proof of this is provided by the fracture pattern of the coating in Fig. 7(f), which shows noticeable areas of plastic deformation. The transformation of the fracture mechanism from a pure brittle fracture to a mixed fracture is reflected in the significantly increased bending strain of the specimens, Fig. 6(b). The significant delay of this transformation compared to the pure A199.0 coating can be explained by the precipitation of a second phase. Only after the network of finely distributed precipitates has been removed and coarsened, the microstructure inside the splats was sufficiently softened to change the fracture mechanism. Furthermore, the strength of the AA7075 alloy is significantly higher than that of pure aluminum A199.0, even in soft-annealed condition, which probably results in different ratios of $\operatorname{Re}$ (splat) and $\sigma_{\mathrm{H}}$ (cohesive) of the two coatings.

\section{Conclusions}

In summary, it was shown that a heat treatment of the investigated coatings can lead to a significant increase in ductility. The pure A199.0 coating and the AA7075 coating showed different behaviors in the bending tests depending on the heat treatment time. The following conclusions can be drawn based on the analysis of the microstructure and the fracture surface after the 3-point bending test:

- Purely brittle failure of both coatings in as-sprayed condition occurs along the splat boundaries

- Transition to mixed fracture happens due to a softening of the microstructure during heat treatment

- There is a significant increase in ductility for a pure A199.0 coating after heat treatment at $T=400{ }^{\circ} \mathrm{C}$ for $t_{\mathrm{HT}}=20 \mathrm{~min}$

- There is a delayed transition to mixed fracture in the AA7075 coating due to the age hardening effect triggered by second phase precipitations. A longer heat treatment time is required to increase ductility and toughness of the coating

Acknowledgments The authors gratefully acknowledge the financial support of the German Research Foundation DFG within the project BO 1979/39 - 1 "Treatments of steel sheets for the high pressure die casting of aluminum/steel sheet-metal hybrids with low gap and distortion formation - BeSt". The authors wish to express special thanks to colleagues at Access e. V. Mr. Oleg Stryzhyboroda and Dr. Ulrike Hecht for conducting the 3-point bending tests and EBSD analysis of the samples.

Funding Open Access funding enabled and organized by Projekt DEAL.

Open Access This article is licensed under a Creative Commons Attribution 4.0 International License, which permits use, sharing, adaptation, distribution and reproduction in any medium or format, as long as you give appropriate credit to the original author(s) and the source, provide a link to the Creative Commons licence, and indicate if changes were made. The images or other third party material in this article are included in the article's Creative Commons licence, unless indicated otherwise in a credit line to the material. If material is not included in the article's Creative Commons licence and your intended use is not permitted by statutory regulation or exceeds the permitted use, you will need to obtain permission directly from the copyright holder. To view a copy of this licence, visit http://creativecommons. org/licenses/by/4.0/.

\section{References}

1. K. Bobzin, L. Zhao, T. Schlaefer, and T. Warda, Application of Cold Spraying for Flux-Free Brazing of Aluminium Alloy 6060, Front. Mech. Eng. China, 2010, 5(3), p 256-260

2. K. Bobzin, L. Zhao, F. Ernst, and K. Richardt, Flux-Free Brazing of Mg-Containing Aluminium Alloys by Means of Cold Spraying, Front. Mech. Eng. China, 2008, 3(4), p 355-359

3. L. Zhao, K. Bobzin, D. He, J. Zwick, F. Ernst, and E. Lugscheider, Deposition of Aluminium Alloy Al12Si by Cold Spraying, Adv. Eng. Mater., 2006, 8(4), p 264-267

4. K. Bobzin, M. Öte, S. Wiesner, and L. Gerdt, Analysis of Coatings Deposited by Brazing and Cold Spraying for Casting Aluminum/Steel Hybrids, in International Brazing and Soldering Conference, April 15-18, 2018, New Orleans, Louisiana (2018)

5. K. Bobzin, M. Öte, S. Wiesner, and L. Gerdt, Surface Pretreatment of Steel Sheets for a Compound Casting Process of lowdistortion and low-gap Aluminium Cast-Steel Sheet Hybrids, in: Tagungsband der 11. Internationalen Konferenz Brazing, High Temperature Brazing and Diffusion Bonding (LÖT 2019), 21-23 Mai, 2019, pp. 112-116.

6. K. Bobzin, M. Öte, S. Wiesner, L. Gerdt, A. Bührig-Polaczek, and J. Brachmann, Effect of Alloying Elements on Growth Behavior of Intermetallic Compounds at the Cold-Sprayed Coating/Steel Interface During Immersion in Aluminum Melt, Inter Metalcast, 2018, 249(1-2), p 712-721

7. G. Sundararajan, N.M. Chavan, and S. Kumar, The Elastic Modulus of Cold Spray Coatings: Influence of Inter-splat Boundary Cracking, J. Therm. Spray Technol., 2013, 22(8), p 1348-1357

8. F. Gärtner, T. Stoltenhoff, J. Voyer, H. Kreye, S. Riekehr, and M. Koçak, Mechanical Properties of Cold-Sprayed and Thermally Sprayed Copper Coatings, Surf. Coat. Technol., 2006, 200(24), p $6770-6782$

9. M.R. Rokni, C.A. Widener, V.K. Champagne, G.A. Crawford, and S.R. Nutt, The Effects of Heat Treatment on 7075 Al Cold Spray Deposits, Surf. Coat. Technol., 2017, 310, p 278-285

10. A. Silvello, Porosity of Ni-Based and Ti-Based Cold-Sprayed Coatings, in: Cold-Spray Coatings. Recent Trends and Future Perspectives. Cavaliere, P. (Hrsg.) (Springer, Cham, 2018), pp. 481-501. 
11. G. Petzow and V. Carle, Metallographisches, keramographisches, plastographisches Ätzen, 6th ed., Borntraeger, Berlin, 1994 ((in German))

12. G. Sha and A. Cerezo, Early-Stage Precipitation in Al-Zn-MgCu Alloy (7050), Acta Mater., 2004, 52(15), p 4503-4516

13. H. Löffler, I. Kovács, and J. Lendvai, Decomposition Processes in Al-Zn-Mg Alloys, J. Mater. Sci., 1983, 18(8), p 2215-2240

14. B. Gault, D. Ponge, D. Raabe, H. Zhao, F. De Geuser, A.K. da Silva, and A. Scczepaniak, Segregation Assisted Grain Boundary Precipitation in a Model Al-Zn-Mg-Cu Alloy, Acta Mater., 2018, 156, p 318-329

15. S.H. de Souza, A.F. Padilha, and A.M. Kliauga, Softening Behavior During Annealing of Overaged and Cold-rolled Aluminum Alloy 7075, Mater. Res., 2019, 22(3), p 76

16. X. Sauvage, A. Ganeev, Y. Ivanisenko, N. Enikeev, M. Murashkin, and R. Valiev, Grain Boundary Segregation in UFG Alloys Processed by Severe Plastic Deformation, Adv. Eng. Mater., 2012, 14(11), p 968-974

17. A.J. Schwartz, M. Kumar, B.L. Adams, and D.P. Field, Electron Backscatter Diffraction in Materials Science, Springer, Boston, 2009

18. G. Gottstein, Physikalische Grundlagen der Materialkunde, Springer, Berlin, 2007 ((in German))
19. American Society for Testing and Materials, ASTM E855 08-Test Methods for Bend Testing of Metallic Flat Materials (2013).

20. H. Renzhong, S. Michiyoshi, M. Wenhua, and F. Hirotaka, The Effects of Heat Treatment on the Mechanical Properties of ColdSprayed Coatings, Surf. Coat. Technol., 2015, 261, p 278-288

21. H. Assadi, F. Gärtner, T. Stoltenhoff, and H. Kreye, Bonding Mechanism in Cold Gas Spraying, Acta Mater., 2003, 51(15), p 4379-4394

22. T. Schmidt, F. Gaertner, and H. Kreye, New Developments in Cold Spray Based on Higher Gas and Particle Temperatures, $J$. Therm. Spray Technol., 2006, 15(4), p 488-494

23. S. Yin, X. Wang, W. Li, H. Liao, and H. Jie, Deformation Behavior of the Oxide Film on the Surface of Cold Sprayed Powder Particle, Appl. Surf. Sci., 2012, 259, p 294-300

24. M. Balog, F. Simancik, O. Bajana, and G. Requena, ECAP vs. Direct Extrusion-Techniques for Consolidation of Ultra-Fine Al Particles, Mater. Sci. Eng. A, 2009, 504(1-2), p 1-7

Publisher's Note Springer Nature remains neutral with regard to jurisdictional claims in published maps and institutional affiliations. 